\title{
ROUTINE AMS DATING OF BONE AND SHELL PROTEINS
}

\author{
RICHARD GILLESPIE*, R E M HEDGES, and M J HUMM
}

Research Laboratory for Archaeology, 6 Keble Road, Oxford, England

\section{INTRODUCTION}

${ }^{14} \mathrm{C}$ dating of bone has been unreliable in comparison with more stable materials such as wood or charcoal. Attempts have been made to use various components or fractions isolated from the raw bone sample; these include dilute acid soluble, dilute acid insoluble, collagen, and gelatin, as well as alkali soluble and insoluble fractions of burned bone, and carbonate or apatite fractions of organic-poor bone. All of these fractions have yielded useful data in some cases, but no single method has proven suitable in all situations. The work reported here describes the isolation and purification of amino acids from the dilute acid insoluble fraction of bone collagen and parchment, with some preliminary experiments on amino acids from shell conchiolin.

\section{SAMPLE SELECTION}

The target preparation system (Wand, Gillespie \& Hedges, 1984) was set up for a sample size at the combustion stage of ca $5 \mathrm{mg}$ carbon, which is equivalent to ca $20 \mathrm{mg}$ of collagen or amino acids. Batches of 20 to 30 bones were assayed for primary amino acids by removing the inorganic matrix with $0.6 \mathrm{M} \mathrm{HCl}$, then forming the trinitrobenzensulfonate (TNBS) derivative from 5 to $10 \mu \mathrm{l}$ aliquots of the hydrolysates (Snyder \& Sobozinsky, 1975 ). Sufficient bone, in the range 0.5 to $10 \mathrm{~g}$, was then carried through the full process to yield ca $20 \mathrm{mg}$ of purified amino acid mixture. Other amino acid analysis techniques that yield the concentration of all amino acids present in hydrolysates, such as ion-exchange chromatography with ninhydrin detection, or DANSYL derivatization with reverse-phase chromatography and UV or fluorescence detection, offer more complete information. Derivatization or detection with OPA, fluorescamine, or other reagents that react only with primary amino acids (and not proline or hydroxyproline) are less satisfactory for deciding which bones are suitable for dating.

\section{BONE PROCESSING}

Batches of 6 to 12 bone samples are convenient for this procedure; it does not require constant attention and a competent technician can process 1 or 2 batches per week while still performing other duties.

1) Cleaning - the surfaces of bones are sandblasted with $30 \mu$ alumina to remove encrustations, then crushed in a stainless steel percussion mortar to pass a $1 \mathrm{~mm}$ screen (a tea strainer works well for this).

2) Dissolution- $20 \mathrm{ml} 0.6 \mathrm{M} \mathrm{HCl}$ at room temperature, with occasional agitation by vortex mixer or shaking, 2 to 24 hours. Centrifuge and discard solution, repeat 2 or 3 times as necessary until no more gas is

* Present address: NSF Regional Accelerator Facility, Department of Physics, University of Arizona, Tucson, Arizona 85721. 
evolved and the solution remains below pH3; wash with $20 \mathrm{ml}$ distilled water, centrifuge again.

3) Hydrolysis- $3 \mathrm{ml} 6 \mathrm{M} \mathrm{HCl}$ at $105^{\circ} \mathrm{C}$ for 16 to 24 hours (overnight).

4) Remove color-dilute to $20 \mathrm{ml}$ with distilled water, add ca $10 \mathrm{mg}$ decolorizing charcoal, heat 10 minutes at $100^{\circ} \mathrm{C}$, cool, centrifuge, and retain the solution.

5) Desalting - pass solution through $5 \mathrm{ml}$ column of cation exchange resin (in hydrogen form), wash column with $50 \mathrm{ml}$ distilled water, discard washings, then elute amino acids with $20 \mathrm{ml} 1.5 \mathrm{M}$ ammonia.

6) Drying - ammonia solution collected in PTFE beaker, evaporated under heat lamp with purified air flow, last 0.5 to $1 \mathrm{ml}$ transferred to combustion tube for final drying at $80^{\circ} \mathrm{C}$ with air flow.

Steps 2, 3, and 4 are carried out in the same $30 \mathrm{ml}$ Pyrex culture tube with PTFE-lined cap; this reduces the number of containers needed and, hence, minimizes laboratory-induced contamination. Even with these precautions, we found it difficult to keep the "total chemistry background" below ca $0.7 \%$ modern (Gillespie \& Hedges, 1984). We tried an extra step of soaking in $0.1 \mathrm{M} \mathrm{NaOH}$ to remove humic acid contamination; but for good collagen, the resulting age was identical with untreated samples, and degraded collagen sometimes dissolved in the alkali, so this step was abandoned. Conversion to graphite and AMS measurement are as previously described (Wand, Gillespie \& Hedges, 1984; Gillespie et al, 1984).

\section{SINGLE AMINO ACID ISOLATION}

As a further stage of purification, proline, and hydroxyproline were isolated from the amino acid mixture prepared as above. This requires much larger samples, since these 2 amino acids constitute only ca $10 \%$ each of the total. The hydrolysate is either treated with nitrous acid (Gillespie, Hedges \& Wand, 1984) or with aqua regia (Stafford et al, 1982) to deaminate the primary amino acids; the nitroso derivatives of the imino acids are destroyed with excess $6 \mathrm{M} \mathrm{HCl}$ and the solution diluted for desalting as above. Hydroxyproline and proline were separated on a Partisil SCX cation exchange column using $\mathrm{pH} 2.5$ phosphate buffer. This final separation is dependent on complete deamination and removal of primary amino acids and their hydroxy acid products because the ion exchange procedure used is unable to isolate one component from a complex mixture. HPLC separation using resin-based cation exchange columns is superior in resolution and may be used to separate some single amino acids (or groups of similar polarity).

\section{PARCHMENT PROCESSING}

Parchment is animal skin, usually sheep or goat, and consists mainly of collagen. The known-age samples dated here were sandblasted with $30 \mu$ alumina, soaked in $0.6 \mathrm{M} \mathrm{HCl}$ for 1 hour, washed with distilled water, soaked in $0.1 \mathrm{M} \mathrm{NaOH}$ for 1 hour, washed again, then hydrolyzed, decolorized with charcoal, and desalted as above. 
TABLE 1

Known-age samples

Parchment*

Collagen amino acids

$\begin{array}{ll}O \times A-418 & 1040 \pm 80\end{array}$

$\begin{array}{lr}O \times A-419 & 970 \pm 80\end{array}$

OxA-420 $750 \pm 80$

Bone

Collagen amino acids

OxA-424** $\quad 300 \pm 60$

\begin{tabular}{lr}
$\mathrm{O} \times \mathrm{A}-425^{*}$ & $1960 \pm 80$ \\
\hline
\end{tabular}

Historical date

AD 1133 (920 BP)

AD $1215 / 1216(850 \mathrm{BP})$

AD 1381 (650 BP)

Historical date

AD 1545 (300 BP)

AD79 or AD61 (1900 or $1930 \mathrm{BP}$ )

*Parchments from Beit-Arie, Jewish National Library.

**This was a pork rib recovered from the HMS Mary Rose, flagship of Henry VIII; OxA425 was a human bone from Pompeii.

\section{SHELL PROCESSING}

Shell fragments were sandblasted with $30 \mu$ alumina and etched in dilute $\mathrm{HCl}$ to remove 10 to $20 \%$ of the surface carbonate. For carbonate dates, the cleaned fragments were treated with $50 \%$ phosphoric acid under vacuum, the carbon dioxide released was dried and converted to graphite as before. For the organic fractions, separate $15 \mathrm{~g}$ shell samples were processed as follows:

1) Excess 2M HCl was added to dissolve the carbonate matrix, the insoluble organic residue was washed with distilled water.

2) Hydrolysis in $6 \mathrm{M} \mathrm{HCl}$ at $105^{\circ} \mathrm{C}$ overnight; dark material, insoluble at this step, was filtered off and dated as "humic acid."

3) The soluble hydrolysate was desalted on the cation exchange resin and dried for combustion as above.

\section{DISCUSSION}

Table 1 shows AMS amino acid dates on known-age parchment and bone. The accuracy and precision are just about adequate for these relatively young samples if authentication is the object of the measurement; other studies may well require better precision $( \pm 20-40 \mathrm{yr}$ uncertainty) for the resolution of small age differences. These results are published in Gillespie et al (1985).

Table 2 shows the results of two experiments where proline and/or

TABLE 2

Proline and hydroxyproline separations*

\begin{tabular}{lcll}
\hline Wooly rhinoceros bone, Northampton & & \\
OxA-98 (AA) & $26,300 \pm 500$ & BM-2074 (C) & $23,880 \pm 770$ \\
OxA-155 (PRO) & $28,800 \pm 1100$ & BM-2074C (AA) & $25,500 \pm 650$ \\
OxA-156 (HYP) & $28,000 \pm 1100$ & & \\
\multicolumn{2}{l}{ Anglo-saxon burial, Essex } & & \\
OxA-96 (C) & $1200 \pm 400$ & BM-2041 (C) & $1270 \pm 100$ \\
OxA-97 (HYP) & $1300 \pm 400$ & BM-2042 (AA) & $1220 \pm 110$ \\
\hline
\end{tabular}

*British Museum dates from Richard Burleigh et al

$\mathrm{C}=$ collagen, $\mathrm{AA}=$ collagen amino acids, $\mathrm{PRO}=$ proline, $\mathrm{HYP}=$ hydroxyproline 




$\mathrm{CH}=$ Charcool, $\mathrm{HA}=$ Humic $A c i d, A A=$ Collogen Amino Acids

Fig 1 . Oxford bone amino acid dates from Pincevent, in France, compared to conventional ${ }^{14} \mathrm{C}$ ages.

hydroxyproline were separated using the method described above (Gillespie, Hedges \& Wand, 1984). The precision of these early measurements is not good enough to make definite conclusions, but the indications are that for the rhinoceros sample, the single amino acid dates are older than either the collagen or total amino acid dates. This is in contrast with results on a mammoth bone, where the imino acids are not the oldest fraction (Donahue, Jull \& Zabel, 1984).

Figures 1 and 2 contain some Oxford bone amino acid dates compared with dates on the same sample or different material from the same horizon, by other famous European laboratories using traditional beta counting on large samples (full details will be published elsewhere). The AMS amino acid dates are at least comparable with, and in most cases slightly older than, results for beta counting; but in all cases, on samples of $<5 \mathrm{~g}$ bone. For those samples older than 20,000 BP, the precision of the AMS dates is lower than that of the traditional dates, the major contribution to the error term being the uncertainty in the background. Experiments to isolate where the contamination comes into the samples during processing have been unclear (Gillespie \& Hedges, 1984). The charcoal treatment for de-

\section{ABRI PATAUD}

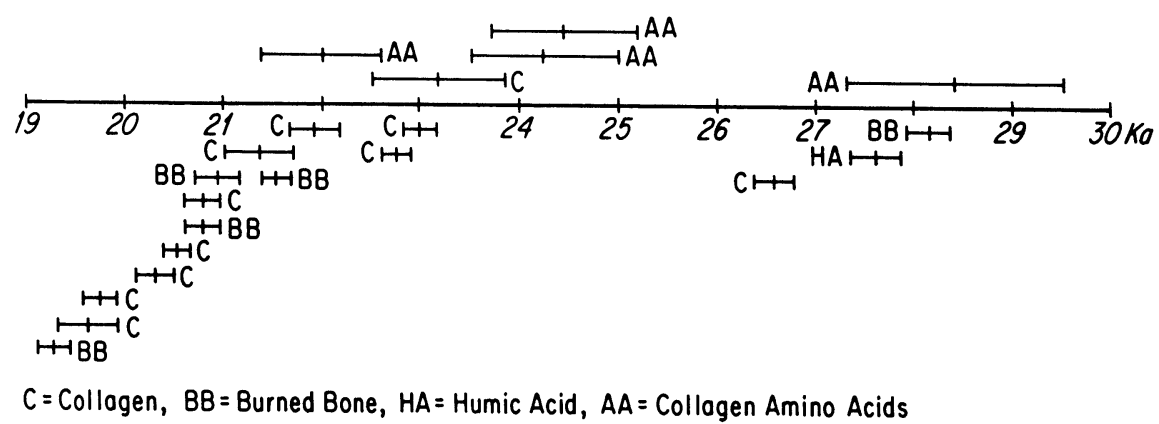

Fig 2. Oxford bone amino acid dates from Abri Pataud, in France, compared to conventional ${ }^{i 4} \mathrm{C}$ ages. 
TABLE 3

Shell data*

\begin{tabular}{|c|c|c|}
\hline $\begin{array}{lr}\text { Rogne, } 1979-132 \mathrm{~A}, \text { Mya truncata } \\
\text { OxA-354 (CO3) } & 12,100 \pm 160 \\
\text { OxA-355 (AA) } & 11,500 \pm 160\end{array}$ & $\mathrm{~T}-3705$ (CO3) & $11,090 \pm 140$ \\
\hline $\begin{array}{lr}\text { Rogne, } 1979-122, \text { Mya truncata } \\
\text { OxA-356 (CO3) } & 39,600 \pm 3000 \\
\text { OxA-357 (AA) } & 27,300 \pm 1100\end{array}$ & T-2658 (CO3) & $37,200 \pm 200$ \\
\hline $\begin{array}{lc}\text { Fjosanger Pr-1610, Gravel I/Sand J, Arctica islandica } \\
\text { OxA-358 (CO3) } & >44,000 \\
\text { OxA-359 (AA) } & 23,000 \pm 800 \\
\text { OxA-360 (HA) } & 17,200 \pm 400\end{array}$ & T-3623 (CO3) & $>58,700$ \\
\hline
\end{tabular}

*Trondheim dates from Mangerud et al $(1981 \mathrm{a}, \mathrm{b})$

$\mathrm{CO} 3=$ carbonate, $\mathrm{AA}=$ conchiolin amino acids, $\mathrm{HA}=$ humic acids

colorizing, first used in 1785 by $\mathrm{J}$ T Lowitz on tartaric acid solutions (Partington, 1962), is perhaps a prime candidate. However, recent experiments performed by RG at Tucson show that a charcoal-treated hydrolysate yields the same age as an untreated hydrolysate, and that reagent-grade $\mathrm{HCl}$ contains organic matter with greater than modern ${ }^{14} \mathrm{C}$ activity. Thus, the background problem is more probably related to the $\mathrm{HCl}$; the use of doubly distilled acid is recommended.

Table 3 shows the results of carbonate and organic dates on marine shells, compared with carbonate dates from traditional beta counting on the same material. Fairly good agreement is noted for the carbonate results by the different methods of measurement, but the amino acid and humic acid dates on the two older samples are significantly different from the carbonate dates. In particular, the Fjosanger sample dates indicate severe contamination of both organic fractions, and it is not clear why this should be so for such well-preserved shells. During the dissolution of the matrix for the organic dates, the "sweaty armpit" odor of low molecular weight carboxylic acids was readily apparent, indicating that some amino acids have been deaminated (Hoering, 1980), though how this mechanism could contribute modern carbon has not been investigated.

\section{CONCLUSIONS}

The technique described here has provided a good supply of data that would otherwise have been impossible or extremely time consuming (ca 200 bones processed). It is clear that the AMS dates produced using a mass production approach on small samples are comparable with traditional large-sample results, at least for well-preserved bone. Poorly preserved bone, with $<$ ca $0.2 \%$ dilute acid insoluble protein cannot be conveniently treated using these methods. Higher precision is needed for the analysis of fractions from such low-carbon bones older than 20,000 BP. There have been too few experiments on the isolation of single amino acids to say whether the extra work is worthwhile or not. For difficult bones, gentler and more selective extraction techniques are needed, with more specific characterization of the dated fractions. The generally low organic carbon content of shells, and the difficulty of isolating pure and specific amino 
acids, may well limit the widespread application of the current methods, but carbonate dates will be as useful as ever.

There are three important implications arising from the AMS ${ }^{14} \mathrm{C}$ results presented here:

1) the more highly purified collagen amino acids and single amino acids yield consistent ages

2) multiple sample dating from single-event horizons, and multiple fraction dating from single bones, can now become routine practice rather than specialist research

3) amino acid racemization dating becomes irrelevant for bones $<\mathrm{ca}$ $40,000 \mathrm{BP}$, since AMS ${ }^{14} \mathrm{C}$ can compete directly in sample size.

REFERENCFS

Donahue, D J, Jull, A J T, and Zabel, T H, 1984, Results of radioisotope measurements at the NSF tandem accelerator facility: Nuclear Instruments \& Methods, v 233(B5), p 162166.

Gillespie, R, Gowlett, J A J, Hall, E T and Hedges, R E M, 1984, Radiocarbon measurement by accelerator mass spectrometry: Archaeometry, v 26, no. 1, p 15-20.

Gillespie, R, Gowlett, J A J, Hall, E T, Hedges, R E M and Perry, C, 1985, Radiocarbon dates from the Oxford AMS system: Archaeometry datelist 2: Archaeometry, v 27, no. 2, p $237-246$.

Gillespie, R and Hedges, R E M, 1984, Laboratory contamination in radiocarbon AMS: Nuclear Instruments \& Methods, v 233(B5), p 294-296.

Gillespie, R, Hedges, R E M and Wand, J O, 1984, Radiocarbon dating of bone by accelerator mass spectrometry: Jour Archaeol Sci, v 1 1, p 165-170.

Hoering, T C, 1980, The organic constituents of fossil mollusc shells, in Hare, P E, Hoering, T C and King, K, Jr, eds, Biogeochemistry of amino acids: New York, John Wiley \& Sons.

Mangerud, J, Gulliksen, S, Larsen, E, Longva, O, Miller, G F, Sjerup, H-P and Sonstergaard, $\mathrm{E}, 1981 \mathrm{~b}$, A Middle-Weichselian ice-free period in western Norway: The Alesund Interstadial: Boreas, v $10, \mathrm{p} 447-462$

Mangerud, J, Sonstegaard, E, Sjerup, H-P and Haldorsen, S, 1981a, A continuous EemianEarly Weichselian sequence containing pollen and marine fossils at Fjosanger, western Norway: Boreas, v 10 , p 137-208.

Partington, J R, 1962, A history of chemistry: London, Macmillan.

Snyder, S L and Sobozinsky, P Z, 1975, Improved 2,4,6-trinitrobenzene-sulfonic acid method for determination of primary amines: Analytical Biochemistry, v 64, p 248-288.

Stafford, T W, Jr, Duhamel, R C, Haynes, C V and Brendel, K, 1982, Isolation of proline and hydroxyproline from fossil bone: Life Sciences, v 31, p 931-938.

Wand, J O, Gillespie, R and Hedges, R E M, 1984, Sample preparation for accelerator based radiocarbon dating: Jour Archaeol Sci, v 11, p 159-163. 